\title{
Contemporary pollen flow, characterization of the maternal ecological neighbourhood and mating patterns in wild cherry (Prunus avium L.)
}

\author{
JE Cottrell ${ }^{1}$, SP Vaughan ${ }^{2,3}$, T Connolly ${ }^{1}$, L Sing ${ }^{1}$, DJ Moodley ${ }^{2}$ and K Russell ${ }^{2}$ \\ ${ }^{1}$ Forest Research, Northern Research Station, Roslin, Midlothian, UK; ${ }^{2}$ East Malling Research, East Malling, Kent, UK and ${ }^{3}$ Rothamsted \\ Research, Harpenden, Herts, UK
}

\begin{abstract}
Conversion of lowland woodland to agricultural land and resulting fragmentation in Britain has been ongoing since Neolithic times. To counteract this decline, plantations of native species, often based on non-British planting stock, have been established. This may ultimately be detrimental to the integrity of the native gene pool. We explore the genetic and ecological factors influencing the success of components of the local pollen pool, including the effect of a nonnative planting on an ancient woodland population of wild cherry. Wild cherry exhibits gametophytic self-incompatibility (GSI) and vegetative reproduction, both of which may be determinants of paternal success. The majority $(61 \%)$ of the successful pollen originated from within the study site with a maximum pollen transfer distance of $694 \mathrm{~m}$. There was a distinct departure from random mating, with over half the
\end{abstract}

successful pollen originating from trees which occur within $100 \mathrm{~m}$ of the mother tree. Self-incompatibility, clonality, tree size and proximity to the mother tree were all found to influence paternal success. Kinship of pollen gametes within a maternal progeny was highest when a mother tree was surrounded by a large number of ramets of a single, compatible clone consisting of large, adult trees. Although the contribution from the non-native plantation is currently low, it is likely that this will increasingly contribute to the progeny of the adjacent ancient population as it matures. The results clearly show that in self-incompatible species, such as $P$. avium, close neighbours may be pollinated by very different components of the local pollen pool.

Heredity (2009) 103, 118-128; doi:10.1038/hdy.2009.39; published online 15 April 2009

Keywords: Prunus; gene flow; pollen; S locus; SSR; self- incompatibility

\section{Introduction}

Gene flow occurs by natural transfer of both pollen and seed, although after colonization by seed, the major mechanism for subsequent gene flow within and among plant populations is mainly through pollen movement (Adams, 1992). Effective gene flow through successful pollination events is therefore a major determinant of the pattern of genetic diversity within and among populations (Streiff et al., 1999). Individuals are known to make unequal paternal contributions to the overall progeny pool (Smouse and Meagher, 1994), and pollination success of individuals has been shown to be influenced by the amount of pollen (Devlin et al., 1992) and flowers produced (Schoen and Stewart, 1986), and by the overall floral display (Broyles and Wyatt, 1995). However, such correlations are not always simple (Handel, 1985; Meagher, 1991; Routley et al., 2004) and a complex web of interacting species-specific ecological and biological factors require consideration if we are to understand the mechanisms underpinning gene flow and the mainte-

Correspondence: Dr JE Cottrell, Ecology Division, Northern Research Station, Forest Research, Roslin, Midlothian, EH25 9SY, Scotland, UK. E-mail: joan.cottrell@forestry.gsi.gov.uk

Received 11 August 2008; revised 4 February 2009; accepted 6 February 2009; published online 15 April 2009 nance of genetic diversity within plant populations. This study is concerned with the genetic and ecological variables that influence pollination success in wild cherry (Prunus avium L.).

The conversion of lowland woodland to agricultural land has been ongoing since Neolithic times and has led to an increasingly fragmented distribution of wild cherry in Britain. In recent years, many new plantations of the native species have been established in an attempt to counteract the decline of this species. However, these new woodlands are frequently based on non-local, or even non-British, planting stock which may ultimately have a detrimental effect on the integrity of the native cherry gene pool (http://www.floralocale.org). An improved understanding of gene flow and mating patterns in this species is required to maintain the native wild cherry genetic resource and to assess the effect of anthropogenic influences on the occurrence of cherry in the British landscape.

Wild cherry (Prunus avium L., family Rosaceae) is a deciduous, entomophilous tree species which is found throughout Europe and Northern Africa. Bees are the main pollinators of wild cherry and many ecological factors, for example, tree size, pollen load, distance between trees etc. are likely to influence pollinator behaviour and thus pollination success. Indeed, in other tree species, it has been shown that the spatial 
arrangement and the local density of the adult trees shape pollen dispersal patterns and a clumped arrangement has been found to favour shorter intermate distances compared with more regular distributions (Handel, 1983; Garcia et al., 2005). Significantly, cherry exhibits a clumped distribution interspersed within mixed woodland (Vaughan et al., 2007a). This is likely to cause the number and distribution of pollen donors around individual mother trees to be highly variable.

In addition, it is likely that the genetic factors of selfincompatibility and clonality will also be major determinants of paternal success in this species, a topic which has been studied in Solanum carolinense, a perennial, herbacaeous species (Elle and Meagher, 2000). Wild cherry exhibits gametophytic self-incompatibility (GSI) whereby incompatibility between individuals is controlled by the multi-allelic $S$ locus and determined by the haploid genotype of the pollen and the diploid genotype of the style (McCubbin and Kao, 2000). GSI prevents both self-fertilization and mating between non-related individuals harbouring identical $S$ alleles (de Nettancourt, 2001; Franklin-Tong and Franklin, 2003). Theoretical models predict that high levels of polymorphism will be maintained at the $S$ locus through frequencydependant selection as rare alleles theoretically have a higher probability of successfully pollinating other individuals (Wright, 1939; Campbell and Lawrence, 1981). In natural wild cherry populations, the distribution and frequency of $S$ alleles is therefore likely to be of major ecological significance (Schueler et al., 2006; Stoeckel et al., 2006). Self-incompatibility is strongly associated with clonal reproduction and it is likely that clonality provides reproductive assurance (Vallejo-Marín and O'Brien, 2007). Asexual reproduction is also common in wild cherry (Stoeckel et al., 2006; Vaughan et al., $2007 \mathrm{~b}$ ) and the presence of clonal groups will probably influence both pollen receipt and production as seen in other species (Handel, 1985).

Earlier studies by our group (Vaughan et al., 2007a) showed a significant non-random genetic structure within ancient semi-natural woodland populations of wild cherry. We observed high overall spatial genetic structure (SGS) values (Sp 0.030-Sp 0.045) when considering only sexually derived genets and kinship coefficients (Fij) significant up to the $120 \mathrm{~m}$ distance class. The inclusion of clonal ramets in the analysis significantly increased the overall SGS (Sp 0.089-Sp 0.119) illustrating the dramatic effect of vegetative propagation on SGS in this species. Neighbourhood size estimates were relatively small for both the managed and unmanaged populations and kinship coefficients declined with distance under both regimes suggesting that common mechanisms may restrict both pollen and seed dispersal in wild cherry. The objective of the current study was to characterize pollination events and gene flow at this site to elucidate some of the ecological factors that may influence the paternal contribution to progeny of different wild cherry mother trees and underpin the strong SGS already observed. We also sought to determine whether the cherry at the study site was genetically isolated from surrounding woods because of the fragmented distribution of cherry in the agricultural landscape and whether there was pollen flow from the adjacent plantation based on non-local material.

\section{Materials and methods}

\section{Study area}

The study site (Figure 1), located at Fawkham Green, Kent, UK (51:21:39N, 0:16:34E) consists of three contiguous woods (A, B and C) each of which contain wild cherry (Prunus avium L.). The appearance of woods A and $\mathrm{B}$ on maps pre-dating 1600AD, the absence of evidence of planting and the presence of many ancient woodland indicator species qualifies them to be classified as ancient, semi-natural woodlands (Kirby and Goldberg, 2003). The trees growing in them are therefore, likely to be the product of natural colonization based on local material. Wood A, (19 hectares) is actively managed by the Woodland Trust whereas wood B, (10 hectares) has been unmanaged for at least 20 years. Wood $C$ (five hectares) is a new plantation established by the Woodland Trust 15 years earlier on open pasture adjacent to wood A. All wild cherry in the study site was located and phenological measurements collected as described earlier (Vaughan et al., 2007a,b). The spatial-genetic structure and clonal composition of wild cherry in these woodlands has been reported earlier (Vaughan et al., 2007a, b). Woods A and B contain 246 genets represented

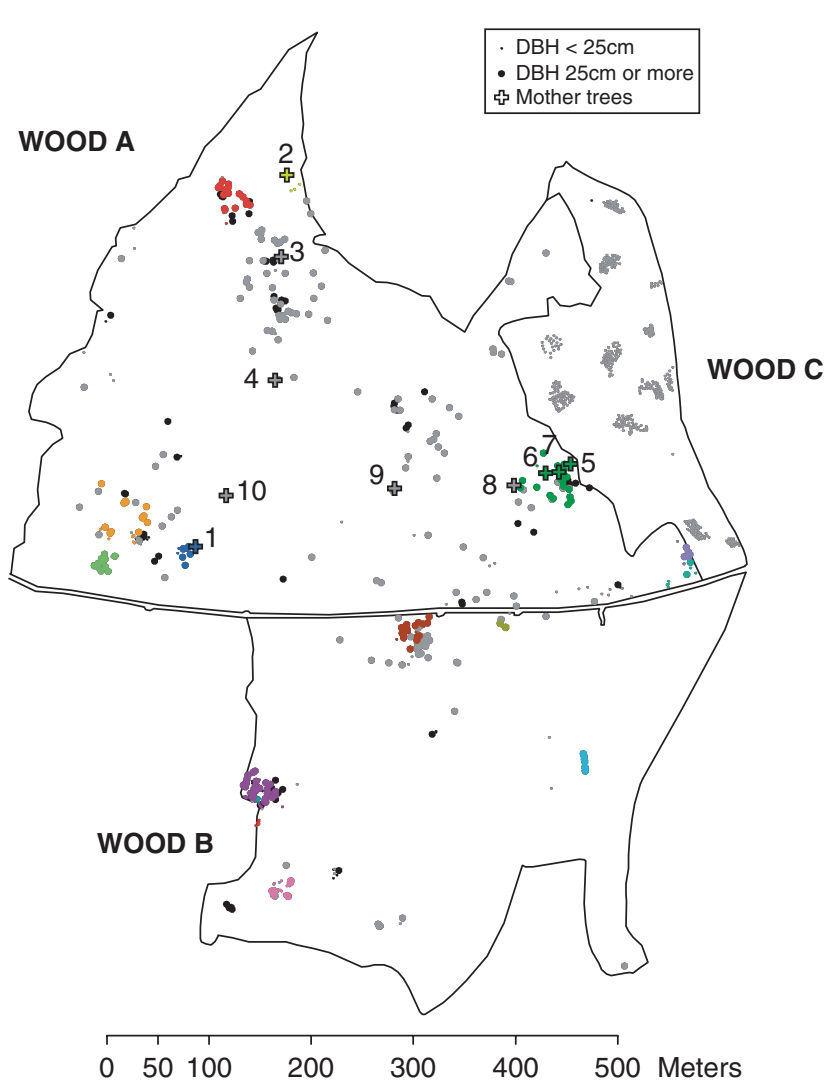

Figure 1 Map showing the distribution of trees in woods A, B and $\mathrm{C}$ on the study site. Coloured dots indicate the large clonal groups (five trees per genet or more). Members of small clonal groups (less than five trees per genet) are shown as black dots. Single ramet genets are shown as grey dots. Small dots indicate trees that have $\mathrm{dbh}<8 \mathrm{~cm}$ and large dots represent trees with $\mathrm{dbh}>8 \mathrm{~cm}$. Crosses indicate the ten mother trees from which seed was collected. The colour of the cross indicates the clonal group of the mother tree. A grey cross indicates that the mother tree is a single ramet genet. 
by 551 trees, whereas wood $\mathrm{C}$ contains 423 genets represented by 427 trees. The entire study site is surrounded by pastureland and the closest neighbouring woodlands lie $600 \mathrm{~m}$ to the north, $1 \mathrm{~km}$ to the south, $750 \mathrm{~m}$ to the west and $150 \mathrm{~m}$ to the east. In all cases, the neighbouring woodlands represent relatively small fragments of woodland and contain some wild cherry.

\section{Sampling, DNA extraction and SSR analysis}

Genomic DNA was extracted from dormant buds, collected from all 978 cherry trees in the study site during the winter of 2002-2003, as described by Vaughan and Russell (2004). In July 2003, seed was harvested from ten mother trees growing in wood A (Figure 1). A total of 419 seeds were collected ranging from 18 to 50 seeds per mother tree. After removal of the outer pericarp and separation of the cotyledons, the exposed embryo was excised and frozen at $-80^{\circ} \mathrm{C}$ before DNA extraction. Five of the mother trees $(3,4,8,9$ and 10) are unique, single ramet genets. Tree 2 is a member of a four ramet genet and tree 1 belongs to a ten ramet genet. Mother trees 5, 6 and 7 belong to the same clonal group consisting of 24 ramets.

Wild cherry from all three woodlands and the seed collected from wood A were genotyped at 13 SSR loci and at the $S$ locus using three PCR multiplexes. Multiplexes A and B were carried out as described in Vaughan and Russell (2004). Multiplex C incorporated primers to assay $S$ haplotype as described by Vaughan et al. (2006) in conjunction with the primers for two further SSR loci; UDP98-412 and PceGA34 (Vaughan et al., 2007b). A minimum of six control samples were included in each 96 well plate to ensure reproducibility of allele scores between plates and two researchers evaluated allele scores independently. Any samples generating ambiguous electrophorograms were repeated to verify the data obtained.

\section{Statistical analysis}

Allele frequencies and diversity indices: Allele frequencies and informativeness of each locus; calculated in terms of expected heterozygosity $\left(H_{E}\right)$ (Nei, 1987), polymorphic information content (PIC) (Botstein et al., 1980), Hardy-Weinberg equilibrium and null allele frequency (Summers and Amos, 1997) were determined using the CERVUS software (Marshall et al., 1998).

Characterization of the potential pollen (PP) donors around each sampled mother tree: Genotypic data, along with tree locations, were used to characterize PP donors in discrete distance classes surrounding each mother tree in terms of the number and size (diameter at breast height; dbh) of all cherry trees, trees belonging to a different genet from the mother tree and trees with $S$ alleles which do not match the mother tree that is, all compatible trees. These categories were sub-divided into trees with $\mathrm{dbh}<8 \mathrm{~cm}$ and trees with $\mathrm{dbh}>8 \mathrm{~cm}$. The number of genets compatible with the mother tree was also recorded along with the number of ramets constituting each compatible clone.

Outcrossing rate: The multilocus outcrossing rate $(\mathrm{tm})$, the average single locus outcrossing rate $(t s)$ and the biparental inbreeding rate $(t m-t s)$ were calculated using
Newton-Raphson likelihood estimation in the program MLTR V3.2 (Ritland, 2002). The standard deviation (SD) for each parameter was calculated from 1000 bootstraps with resampling among families. For $95 \%$ confidence intervals $(\mathrm{CI})$ parametric limits were calculated using the reported MLTR mean $\pm 1.96 \times$ s.d. while bootstrap limits were determined from the upper and lower $2.5 \%$ tails of the realized bootstrap values.

Paternity assignment (simple exclusion and likelihood estimates): The contribution of trees from wood $C$ to the paternity of the tested seeds was calculated by simple exclusion using the CERVUS software (Marshall et al., 1998). This approach was used because the allele composition of wood $\mathrm{C}$ based on non-local planting stock was very different from that of populations $\mathrm{A}$ and $B$ and, in nearly every case, the identification of a pollen donor as originating from wood $C$ was unambiguous. Pollen flow from within and outside woods A and B was calculated using the likelihood approach based on the program FAMOZ using the allele frequencies for woods $\mathrm{A}$ and $\mathrm{B}$ as the basis for simulations (Gerber et al., 2003).

For the FAMOZ analysis, empirical tests were conducted in which 10000 simulated offspring were generated. The simulations for paternity were designed to generate offspring on the basis that they originate from either 'inside' or 'outside' woods A and B using three levels of mistyping $(0,0.01$ and 0.1$)$. The most likely pollen donor among the genotyped population of these simulated offspring was then identified and the likelihood ratio or $\log$ of odds ratio (LOD) score recorded and distribution curves produced for the frequency of LOD scores for each simulation. The threshold for distinguishing between paternity from inside and outside the plot was set at the intersection of the two distribution curves. For the paternity analysis, the curves for pollen donors from inside or outside woods A and B showed minimal overlap at the three levels of mistyping.

The empirical tests were then applied to simulated data in which 10000 offspring were randomly generated with the pollen donor from either inside or outside the plot. The number of correct decisions using the threshold LOD generated in the earlier empirical tests was recorded for the three levels of mistyping and two population sizes $(N=500$ or 1000$)$. With zero mistyping, the percentage of correct assignment to pollen donors from either inside or outside was over 93\% irrespective of population size. Similarly, the ability of FAMOZ to identify the correct pollen donor that is, from outside woods A and B or the correct tree within woods A and B was also good with $86 \%$ correct classifications at $0 \%$ mistyping, $86.03 \%$ correct classifications at $0.01 \%$ mistyping and $85.57 \%$ correct classifications at $0.1 \%$ mistyping. Thus, the inclusion of a small degree of mistyping had only a nominal effect on the percentage of correct classifications.

Using the LOD scores for zero mistyping, FAMOZ was then used to assign the most likely pollen donor on the basis of highest LOD score to each of the 419 embryos that were analyzed. In order to confirm that the assigned parents of each seed were compatible, the diploid $S$ allele genotype of the most likely paternal parent of each seed was then examined to check that it differed from that of the maternal parent. 
When a single spatial position was required to represent a group of identical genets for the paternity analysis the topographic mid point of the clonal group was calculated and used to represent the position of the clone in question.

Direction of pollen flow: The azimuth between each mother tree and each compatible genet and each identified siring genet formed the PP and actual pollen (AP) dispersal directions, respectively. Circular histograms, mean direction $(\theta)$ and mean length (R) were determined using GENSTAT. The Rayleigh test for uniformity and two-sample Watson-Williams test of mean directions (Batschelet, 1981) were calculated using SAS macros (Kolliker; see http:// evolution.unibas.ch/koelliker/misc.htm) with $p$-values approximated using a randomization procedure with 5000 iterations.

Relatedness among pollen gametes: The relatedness between the two pollen donors of every pair of offspring of the same or different mothers was estimated using a pairwise kinship coefficient (Hardy et al., 2004; Oddou-Muratorio et al., 2006). The maternal alleles were subtracted from the seed genotype to obtain the paternal contribution to each seed and the pairwise kinship coefficient (Fij) between the paternal gametes of the progeny pairs was computed. The Fij values were obtained using the method developed by Loiselle et al. (1995) using the software program SPAGEDI (Hardy and Vekemans, 2002). SPAGEDI allowed us to obtain the average Fij for pollen gametes within the progeny of each mother tree $(F S)$ and also the average kinship of pollen gametes for progeny among pairs of mother trees $(F g h)$.

Correlation of kinship and ecological maternal variables: The correlation between the genetic variable, kinship for pollen gametes within progeny of each mother tree $(F s)$ and several key ecological maternal variables in specified $5 \mathrm{~m}$ distance classes from each mother tree was calculated. The ecological variables examined in each distance class were I. total number of compatible trees, II. total number of compatible trees with $\mathrm{dbh}>8 \mathrm{~cm}$, III. number of trees belonging to the most common compatible genet and IV. number of trees with $\mathrm{dbh}>8 \mathrm{~cm}$ belonging to the most common compatible genet.

\section{Results}

\section{Allele frequencies and diversity indices}

The SSR allele frequencies and diversity indices for woods A and B have been described earlier (Vaughan et al., 2007a,b). In summary, 116 alleles were identified across 13 SSR loci for the 551 trees in woods A and B and the majority of loci were highly polymorphic and informative. Analysis showed that woods A and B could be considered a genetic continuum of each other. Inclusion of a further 431 trees from wood $\mathrm{C}$ increased the total number of alleles identified to 168 . Of the 168 alleles observed, 11, 9 and 52 were found to be exclusive to woods $\mathrm{A}, \mathrm{B}$ and $\mathrm{C}$, respectively. The relative informativeness of each SSR locus across the three study sites was evaluated using several measures of polymorphism and heterozygosity (Supplementary Table 1).
Deviation from Hardy-Weinberg equilibrium was observed for only one of the 13 loci examined in each of the two ancient semi-natural woods (UDP98-412 in wood A and EMPaSO2 in wood B). In contrast, seven of the 13 loci examined in wood $C$ deviated significantly from HardyWeinberg equilibrium $(P<0.01)$ reflecting the artificial nature of this population.

A total of $16 S$ alleles were identified in wood A, 14 in wood B and 25 in wood C. The presence of six new $S$ alleles in wood $C$ has been reported earlier (Vaughan et al., 2008) and strongly suggests that non-local trees were used to establish wood C, although no planting records were maintained. While the majority of the new $S$ alleles discovered in wood $C$ have not thus far been identified elsewhere in the world, two of the alleles occur in wild cherry from Iran, suggesting that the planting material may have an origin beyond the limits of Western Europe (Vaughan et al., 2008).

\section{Characterization of the PP donors around each sampled mother tree}

The general distribution of trees in the study site is illustrated in Figure 1. Wild cherry in the study site exhibits a markedly clumped distribution (for detailed analysis see Vaughan et al., 2007a,b). As such, the ecological neighbourhood around each mother tree differs greatly. To describe this variation in more detail, we characterized the composition of the trees from woods A and B surrounding each mother tree in $100 \mathrm{~m}$ distance classes (Figure 2). The number of cherry trees surrounding each mother in each distance class differed greatly (Figure 2). However, numbers of trees alone do not represent the actual quantity of PP donors. Trees belonging to the same clone as the mother tree, as well as those of a different genet but sharing the same $S$ alleles, cannot serve as pollen donors. On average, excluding ramets of the same genet as the mother tree resulted in a $16 \%$ decrease in PP donors within $100 \mathrm{~m}$ of the mother tree. However, this loss did not occur evenly across all mother trees; mother trees 3, 4, 8, 9 and 10 were single ramet genets and therefore lost no PP donors through common clonal membership. In contrast, $62 \%$ of the trees within $100 \mathrm{~m}$ of mother trees 5, 6 and 7 belonged to the same clone as the mother tree and were therefore incompatible as pollen donors.

Incompatibility, because of different genets sharing the same $S$ alleles, led to a further reduction of $12 \%$ of PP donors over the ten mothers in the first $100 \mathrm{~m}$ distance class. Once again, this was not evenly distributed across all mother trees and was most marked in trees 5, 6 and 7 (Figure 2).

The size $(\mathrm{dbh})$ of the trees surrounding the mother trees was also found to be highly variable. On average, $21 \%$ of compatible trees within the first $100 \mathrm{~m}$ were $\mathrm{dbh}<8 \mathrm{~cm}$. However, once again this figure was highly variable when considered on an individual mother tree basis. For example almost half of compatible trees within the first $100 \mathrm{~m}$ of mother tree 1 has a $\mathrm{dbh}<8 \mathrm{~cm}$ (Figure 2).

The clonal composition of the compatible trees with $\mathrm{dbh}>8 \mathrm{~cm}$ within $100 \mathrm{~m}$ of each mother tree is presented in Figure 3. This clearly illustrates that the composition of the sizeable, compatible trees around each mother tree is variable. For example, mother trees 5, 6 and 7 have 


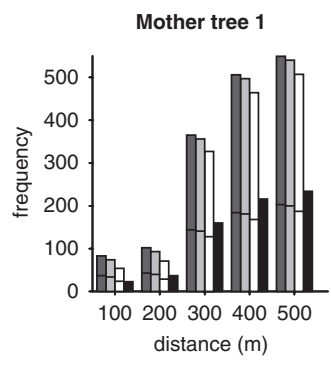

Mother tree 6

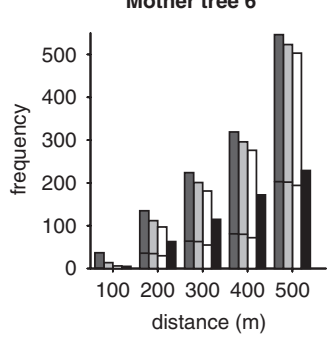

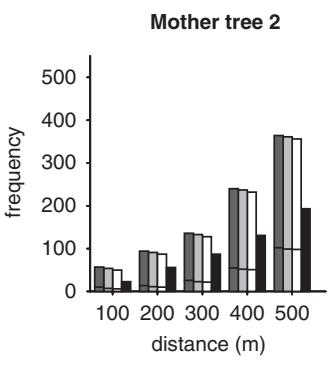

Mother tree 7

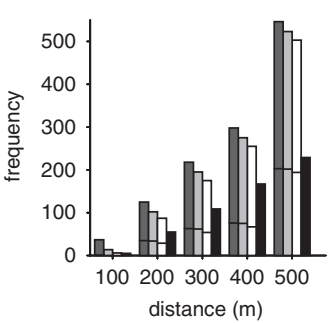

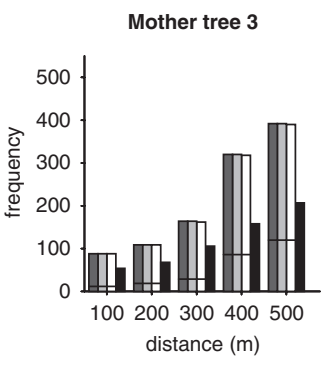

Mother tree 8

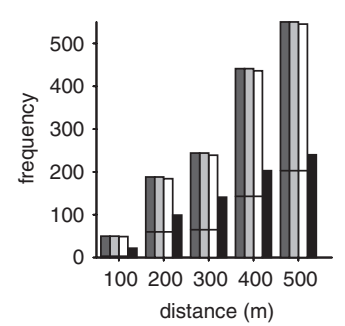

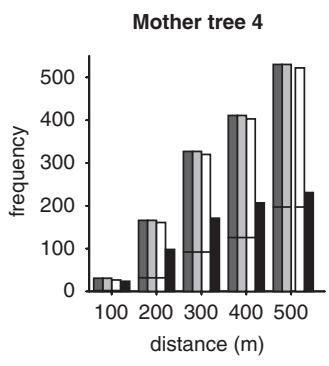

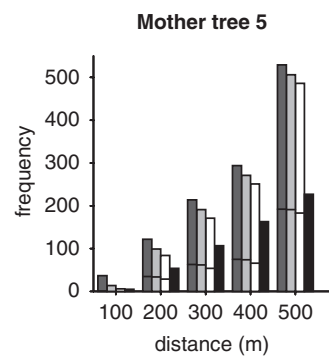

Mother tree 9

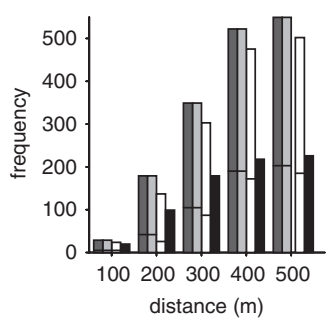

Mother tree 10

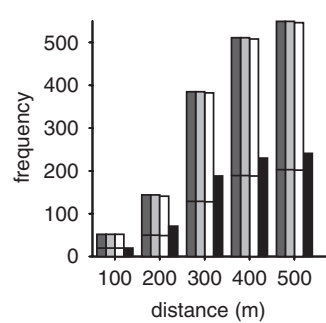

Figure 2 Diagrams illustrating the conspecific neighbourhood of trees in the semi-natural woods (woods A and B) around each mother tree in increments of $100 \mathrm{~m}$. (Key: dark grey=all wild cherry trees, light grey=all trees that belong to a different genet from mother tree, white $=$ all trees with $S$ alleles which do not match the mother tree, black= all compatible genets. The horizontal bar indicates the proportion with $\mathrm{dbh}<8 \mathrm{~cm}$ (below bar) and with $\mathrm{dbh}>8 \mathrm{~cm}$ (above bar).

only five compatible genets in this distance class and these are composed of four single ramet clones and one dual ramet clone. In complete contrast, tree 3 is surrounded by 48 compatible genets which contain trees with $\mathrm{dbh}>8 \mathrm{~cm}$ consisting of 41 single ramet genets, one genet with 17 ramets and a further six genets represented by two or three ramets.

\section{Outcrossing rate}

As expected for a species which displays GSI, the multilocus outcrossing rates for each mother tree did not differ significantly from $1.00(t m=0.999$, s.d. $=0.037$, parametric $95 \%$ CI $(0.926,1.072)$ and bootstrap CI $(0.986$, $1.200)$ ). Also, there was no evidence that $t m$ differed from $t s$, that is, that the biparental inbreeding rate differed from zero $(t m-t s=0.034$, s.d. $=0.041$, parametric $95 \% \mathrm{CI}$ $(-0.046,0.114)$ and bootstrap CI $(-0.014,0.199)$.

\section{Paternity analysis}

Contribution to paternity of seeds by trees from wood C: A total of 24 seeds were unambiguously the product of pollen originating from trees in wood $\mathrm{C}$, based on simple exclusion analysis. For the majority of these (20 seeds) a single pollen donor from $C$ was identified. In the remaining four seeds, two or three trees in wood $C$ could have been the pollen donor. A further five seeds were ambiguously fathered by candidates from woods A, B or C. Therefore, the contribution of trees growing in wood $\mathrm{C}$ to the paternity of seed sampled in wood A was between 5.7 and $6.9 \%$. Of the seed unambiguously fathered by pollen donors in wood C, $79 \%$ were produced by the four mother trees growing in close proximity to wood C (mother trees 5 (9 seeds), 6 (5 seeds), 7 ( 3 seeds), 8 ( 2 seeds)). The remaining $21 \%$ were produced by mother trees 4 ( 2 seeds) and 9 ( 3 seeds). The remaining four mother trees, growing furthest from wood C, produced no seed that was fathered by wood $C$. When considered on a per genet

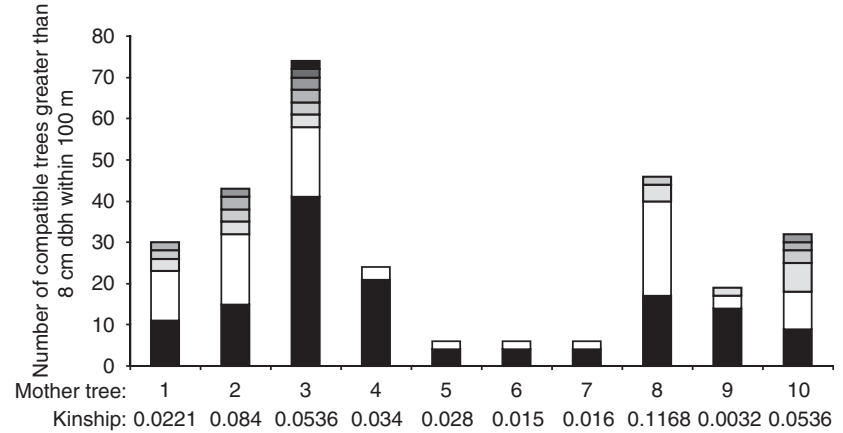

Figure 3 The clonal composition of the compatible trees with $\mathrm{dbh}>8 \mathrm{~cm}$ within $100 \mathrm{~m}$ of each mother tree. The number of single ramet genets is shown in black, the number of ramets representing the most common clonal genet is shown in white. Clonal genets consisting of fewer ramets are shown in various shading patterns in decreasing order of the number of ramets per clone per distance class. The mother tree number and pollen gamete kinship within the progeny of each mother tree $(F s)$ are shown beneath each bar chart.

basis, the contribution of $6-7 \%$ is extremely low in view of the presence of 423 genets in wood C compared with 246 in woods A and B.

Contribution to paternity of seeds by trees within woods $A$ and $\mathrm{B}$ : On the basis of the FAMOZ analysis, the highly polymorphic nature of the SSR markers resulted in an exclusion probability for paternity of 0.9997 when all 13 SSR loci were considered. In decreasing order, the loci which provided the highest exclusion probabilities were; PceGA34, EMPaS06, UDP98-412, EMPaS02 and EMPa018.

In total, 246 seeds had at least one PP donor with an LOD score above the threshold from within woods A and B. A single, unambiguous pollen donor was found for 205 of these and no instances of self-pollination were detected. Assuming $N=1000$ and zero mistyping, cryptic gene flow was $8 \%$. On average (with the correction for 
cryptic gene flow), trees from outside woods A and B accounted for $44.4 \%$ of the paternity of the seed crop produced by the ten sampled mother trees (Table 1). On an individual mother tree basis, the proportion of pollen donors from outside woods A and B ranged from $22.2 \%$ for tree 10 to $78.9 \%$ for tree 5 (Table 1). Part of the reason for the high proportion of pollen donors from beyond woods $\mathrm{A}$ and $\mathrm{B}$ to mother tree 5 was the contribution from wood $C$, but even when this is taken into account this mother tree, which grows near the edge of wood $A$, receives the highest proportion of pollen from outside the study site.

There was departure from random mating in the seed crop of the ten mother trees with an excess of pollen donors in the first distance class (Figures $4 a$ and $b$ ); on average, half the known pollen donors occurred within $100 \mathrm{~m}$ of the mother tree but $<10 \%$ of compatible pollen donor genets grew within this distance. Mother trees differed in the proportion of pollen that came from each distance class (Figure 4a). They also differed in the proportion of seed they produced that was pollinated by close neighbours in woods A and B. For example, pollen sources within $200 \mathrm{~m}$ pollinated only $10 \%$ of the seeds analyzed from mother tree 5 compared with $76 \%$ of the seeds analyzed from mother tree 8 . The maximum pollination distance identified within woods $\mathrm{A}$ and $\mathrm{B}$ was $694 \mathrm{~m}$. Furthermore, seven of the seeds with identified pollen donors from within woods A and B had pollen donors that were located more than $400 \mathrm{~m}$ from the mother tree. In contrast, the maximal distance between an identified pollen donor in wood $\mathrm{C}$ and a mother tree in wood A was $356 \mathrm{~m}$ which is about half that of the maximal distance of an identified pollen donor within $\mathrm{A}$ and $\mathrm{B}$.

Of the successful pollen donors which grew within $200 \mathrm{~m}$ of each of the ten mother trees, the trees with a dbh $>8 \mathrm{~cm}$ made a greater contribution than expected given the observed size distribution of compatible trees in woods A and B within this distance class (data not shown). Size of the pollen donor is therefore an important determinant of paternal success.

Table 1 Paternity of embryos by fathers from populations A, B and C. Cryptic gene flow is estimated at $8 \%$ and is accounted for below in the estimate of pollen donors from outside populations A and B

\begin{tabular}{|c|c|c|c|c|c|c|c|}
\hline $\begin{array}{l}\text { Mother } \\
\text { tree }\end{array}$ & $\begin{array}{c}\text { Number of } \\
\text { embryos } \\
\text { analyzed }\end{array}$ & $\begin{array}{c}\text { Number of } \\
\text { unambiguous } \\
\text { pollen donors from } \\
\text { population } C\end{array}$ & $\begin{array}{c}\text { Pollen donors from } \\
\text { inside populations } \\
A \text { and } B \\
\text { (Uncorrected) }\end{array}$ & $\begin{array}{c}\text { Pollen donors from } \\
\text { outside } A \text { and } B \\
\text { (Apparent) }\end{array}$ & $\begin{array}{l}\text { Pollen donors } \\
\text { from outside } \\
A \text { and } B \text { (True) }\end{array}$ & $\begin{array}{l}\text { Percentage of } \\
\text { pollen donors } \\
\text { from outside } \\
\quad A \text { and } B\end{array}$ & $\begin{array}{l}\text { Percentage of } \\
\text { pollen donors from } \\
\text { outside } A, B \text { and } C\end{array}$ \\
\hline 1 & 45 & 0 & 27 & 18 & 19 & 42.2 & 42.2 \\
\hline 2 & 46 & 0 & 29 & 17 & 18 & 39.1 & 39.1 \\
\hline 3 & 50 & 0 & 33 & 17 & 18 & 36.0 & 36.0 \\
\hline 4 & 49 & 2 & 32 & 17 & 18 & 36.7 & 32.7 \\
\hline 5 & 38 & 9 & 10 & 28 & 30 & 78.9 & 55.3 \\
\hline 6 & 47 & 5 & 26 & 21 & 23 & 48.9 & 38.3 \\
\hline 7 & 34 & 3 & 18 & 16 & 17 & 50.0 & 41.2 \\
\hline 8 & 50 & 2 & 40 & 10 & 11 & 22.0 & 18.0 \\
\hline 9 & 43 & 3 & 17 & 26 & 28 & 65.1 & 58.1 \\
\hline 10 & 18 & 0 & 14 & 4 & 4 & 22.2 & 22.2 \\
\hline Total & 419 & 24 & 246 & 174 & 186 & 44.4 & 38.7 \\
\hline
\end{tabular}
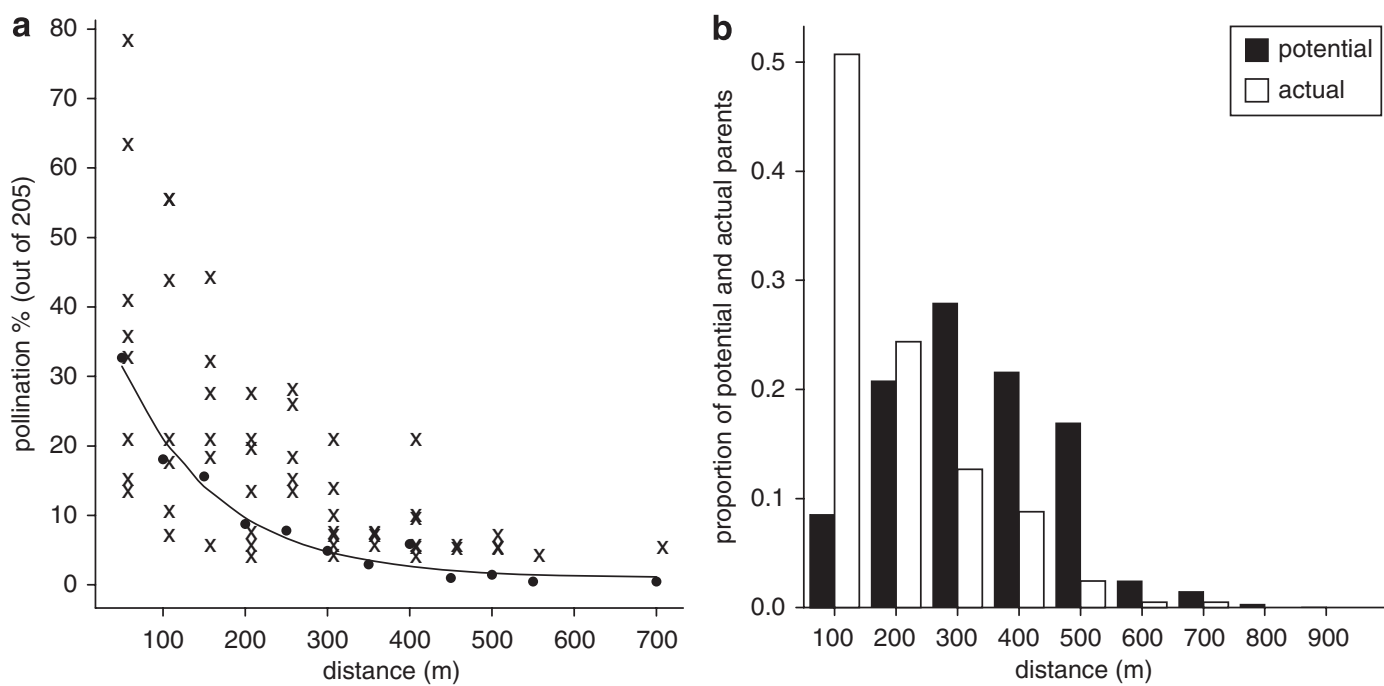

Figure 4 (a) The distribution of actual pollen (AP) donors from the semi-natural woods $\mathrm{A}$ and $\mathrm{B}$ as a function of the distance between maternal and paternal parent pairs. Crosses represent, for individual mother trees, the mating frequencies in each distance class as a proportion of all the pollination events for which a single unambiguous pollen donor was identified. The black circles represent the average value over the ten mother trees. The line represents the exponential curve which describes the mating frequencies in each distance class averaged over the ten mother trees $\left(y=1.017+46.39 \times 0.99161^{x}, R^{2}=0.966\right)$. (b) The proportion of potential, compatible genets and actual pollen (AP) donors from the semi-natural woods A and B in each $100 \mathrm{~m}$ distance class around each mother tree pooled for ten mother trees. 

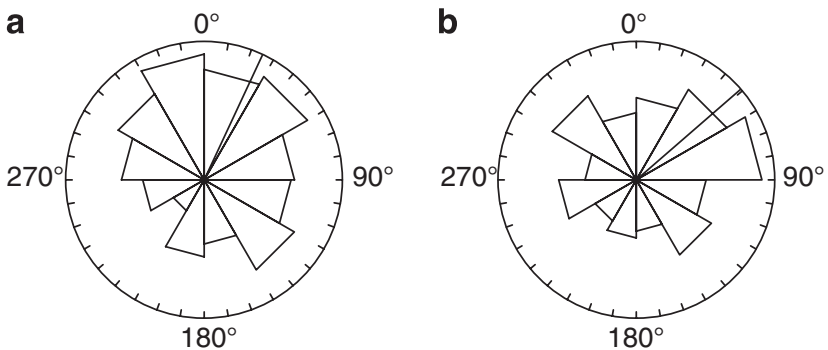

Figure 5 Circular histograms showing the proportion of (a) compatible genets and (b) actual pollination events averaged for the ten mother trees in units of $30^{\circ}$. The mean direction of pollen flow is indicated by the thick black line.

Table 2 The number of progeny analyzed and the kinship of pollen gametes within the progeny of each mother tree $(F s)$

\begin{tabular}{lccc}
\hline Mother tree & Number of progeny analyzed & Kinship Fs & s.e. \\
\hline 1 & 45 & 0.0221 & 0.0044 \\
2 & 46 & 0.0840 & 0.0061 \\
3 & 50 & 0.0536 & 0.0051 \\
4 & 49 & 0.0344 & 0.0052 \\
5 & 38 & 0.0280 & 0.0064 \\
6 & 47 & 0.0146 & 0.0055 \\
7 & 34 & 0.0165 & 0.0069 \\
8 & 50 & 0.1168 & 0.0058 \\
9 & 43 & 0.0032 & 0.0045 \\
10 & 18 & 0.0536 & 0.0148 \\
\hline
\end{tabular}

Standard errors (s.e.) for kinship values are also included.

Direction of pollen flow: Both PP and AP circular histograms differed from a uniform distribution $(P<0.001)$, with an estimated mean vector $\theta=24.95^{\circ}$ and $R=0.300$ for $\mathrm{PP}$, and $\theta=49.02^{\circ}$ and $R=0.294$ for $\mathrm{AP}$ (Figure 5). The PP and AP pollen dispersal directions differed significantly $(P=0.02)$.

Relatedness among pollen gametes within and between maternal progenies: Kinship estimates for the pollen gametes within progeny of each mother tree $(F s)$ are presented in Table 2. The average kinship of pollen gametes within each of the ten maternal progenies was 0.0427 and ranged from 0.0032 for mother tree 9 to 0.1168 for mother tree 8 . These kinship values mean that the probability of co-paternity, that is, the probability of two maternal siblings being sired by the same father, within mother tree seed progenies ranges from 0.6 to $23 \%$.

The average kinship of pollen gametes among maternal progenies $(F g h)$ decreased with increasing distance between mother trees and was never $>0.0224$ (Figure 6). However, the Fgh values for the kinship of pollen gametes among mother tree 8 and its three closest trees with sampled progeny (mother trees 5, 6 and 7) are low. This is because tree 8 receives a considerable proportion of pollen from the large, compatible, multi-ramet clone which includes trees, 5, 6 and 7 . In this situation selfincompatibility dictates that kinship amongst the paternal complement is necessarily low as self-pollination within the clone may not occur. Thus, the clonal neighbourhood and $S$ allele composition of the surrounding trees seem to play a key role in determining paternity.

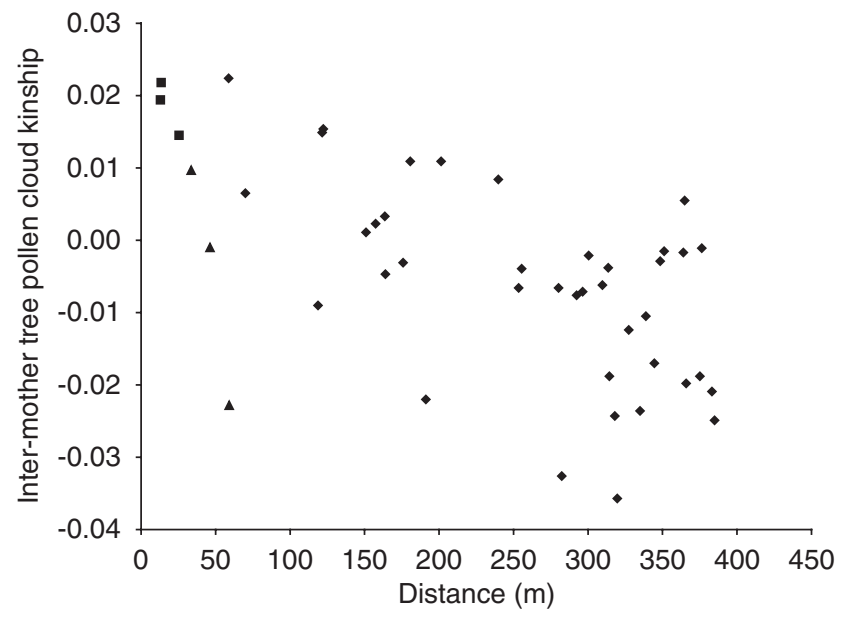

Figure 6 The average kinship of pollen gametes for progeny among pairs of mother trees $(F g h)$ plotted against the geographic distance between each pair of mother trees. Squares represent the $F g h$ values for the mother tree pairs $5 / 6,6 / 7$ and $5 / 7$ which grow in close proximity and belong to the same clone. Triangles represent the $F g h$ values for mother tree pairs $5 / 8,6 / 8$ and $7 / 8$ which grow in close proximity but belong to different clones. Diamonds represent the $F g h$ values for all other mother tree pairs.

Correlation between kinship for pollen gametes within a maternal progeny and ecological neighbourhood variables: The clonal composition of the compatible trees with a dbh $>8 \mathrm{~cm}$ within $100 \mathrm{~m}$ of each mother tree is shown in Figure 3. It can be seen from Figure 3 that average kinship for pollen gametes within a maternal progeny, $(F s)$ tends to be low when there are few compatible trees with $\mathrm{dbh}>8 \mathrm{~cm}$ in the neighbourhood and when the most common genet within the distance class is represented by a low number of ramets. Conversely, Fs is high when many compatible trees with $\mathrm{dbh}>8 \mathrm{~cm}$ are present and the number of ramets of the most common clone is high.

In order to test whether these relationships hold true over a broad range of distances, maternal ecological neighbourhoods were further characterized over a range of distances from the mother trees in terms of four key ecological variables: I. total number of compatible trees, II. total number of compatible trees with $\mathrm{dbh}>8 \mathrm{~cm}$, III. number of trees belonging to the most frequent compatible genet and IV. number of trees with $\mathrm{dbh}>8 \mathrm{~cm}$ belonging to the most frequent compatible genet. The genetic variable $F s$ showed significant correlation $(P<0.05)$ with all four of the ecological variables over at least some of the distance classes (Figure 7). However, the correlation was sustained over a greater distance range when only trees with $\mathrm{dbh}>8 \mathrm{~cm}$ were considered. Variable II was significantly correlated with $F s$ at distance classes between $80 \mathrm{~m}$ and $160 \mathrm{~m}$ from the mother tree and variable IV exhibited a significant correlation at distance classes $25-175 \mathrm{~m}$ (Figure 7). Thus, clonality influences paternal success in P. avium and the degree of success is compounded both by the number and size of individual ramets of compatible clones.

\section{Discussion}

There was a clear departure from random mating in the seed crop of the ten mother trees with almost half of the 


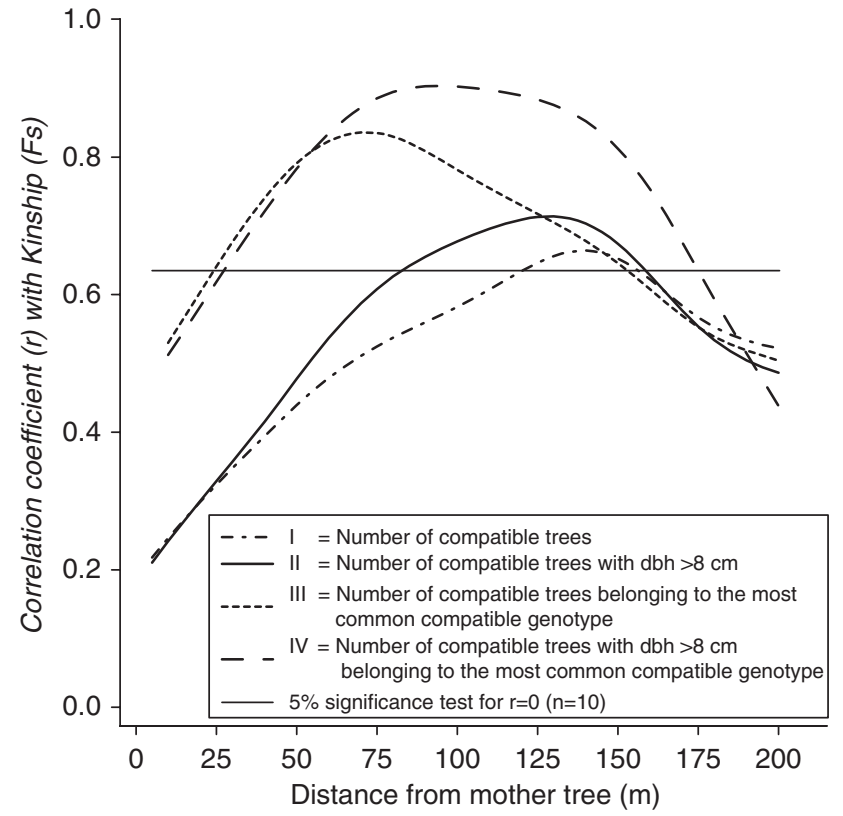

Figure 7 Correlation coefficient over a range of distance classes for the genetic variable, pollen gamete kinship within maternal progenies $(F s)$ and four ecological variables. The horizontal line indicates the point at which there is significant correlation between kinship and the ecological variable. The distance classes increase in $5 \mathrm{~m}$ increments from mother tree. The ecological variables are based on compatible trees from the semi-natural woods A and B. The ecological variables are described in the key attached to the figure.

known pollen donors occurring within $100 \mathrm{~m}$ of the mother tree and this agrees with similar findings in other tree species (Streiff et al., 1999; Geng et al., 2008; Biscaia de Lacerda et al., 2008). Less than $10 \%$ of compatible pollen donor genets grew within this distance and as such it seems that insect pollinator behaviour must be a key determinant of paternal success in wild cherry. This finding underpins the strong SGS observed earlier at this site in distance classes up to $120 \mathrm{~m}$ (Vaughan et al., 2007a) as a prevalence of short-distance pollination events would increase the kinship coefficient of individuals at this scale. However, mother trees differed greatly in the proportion of seed they produced that was pollinated by close neighbours and our analysis indicated that tree size and membership of a clonal genet were primary variables in determining pollination success.

\section{Wild cherry in a 'fragmented' landscape and the effect of non-local plantings}

One of our main objectives was to determine whether the cherry at the study site was genetically isolated from surrounding woods because of the fragmented distribution of cherry in an agricultural landscape. With the correction for cryptic gene flow, $44.4 \%$ of pollination events were from pollen donors outside woods A and B. This was only reduced to $38.9 \%$ when pollen donors from wood $C$ were discounted. This proportion of pollen immigration is much higher than the value of $9.5 \%$ obtained by Garcia et al. (2005) for Prunus mahaleb. One reason for the lower immigration in $P$. mahaleb may be that this species is gynodioecious and only partially selfincompatible. Indeed, Garcia et al. (2005) found that the outcrossing rate was higher in female than hermaphrodite trees (c.f. 1.01 high density, female; 1.01 low density, female; 0.49 high density, hermaphrodite; 0.41 low density, hermaphrodite)

Other reasons for the difference in immigration rates between the two studies may relate to other factors such as tree density $(\sim 14.6$ genets/ha vs. $\sim 8.4$ genets/ha), distance from neighbouring populations $(1.5 \mathrm{~km}$ vs. $150 \mathrm{~m}-1 \mathrm{~km})$ and wind conditions. The Garcia et al. (2007) site is located at an altitude of $1615 \mathrm{~m}$ above sea level (asl) whereas our study site is at $\sim 150 \mathrm{~m}$ asl. Insect flight distances may be longer in the lower altitude site where conditions are likely to be less windy. The maximum foraging ranges of four UK species of bumblebee (Bombus spp.), which are one of the main pollinators of wild cherry, are estimated to range from 449 to $758 \mathrm{~m}$ (Knight et al., 2005) and recent evidence from radio tracking has showed that bee flight distances are significantly shorter in poor weather conditions (Pasquet et al., 2008). Foraging patterns across this range would account for the long-distance pollination events observed in our study. In Sorbus aucuparia, another insectpollinated, self-incompatible Rosaceous species, Bacles et al. (2004) found one of the lowest pollen to seed dispersal ratios that has ever been detected in highly fragmented populations. Bacles et al. (2004) suggested that low pollen dispersal arose from localized foraging of pollinators and infrequent travel between remnant populations at their windy site. The effect of isolation on pollen immigration was further highlighted in a study of two Sorbus torminalis woods, one of which was part of a continuous large population and the other a small more-isolated population (Hoebee et al., 2007). In the continuous population, immigrant pollination accounted for $36-39 \%$ of paternity compared with only $8 \%$ in the isolated population. Therefore, while our study site seems to exist in a fragmented woodland landscape, our results suggest that our sampled mother trees are, in effect, part of a large continuous population in terms of pollen flow.

Our study showed that wood C, which is based on non-locally sourced planting material, contributed $<7 \%$ to the paternity of the seeds tested. This is despite the fact that wood C contains 426 genets compared with only 246 in woods A and B. Furthermore, although the wild cherry here was only 12 years old, the abundant light and space available caused many to flower profusely. There was also a marked NE to SW bias in AP dispersal angles within woods $\mathrm{A}$ and $\mathrm{B}$. If this directional effect also holds true for wood $C$, then this should act to encourage pollen flow from wood $C$ to wood $A$. When these factors are taken into account, the current contribution to paternity of seeds in wood $A$ is surprisingly low.

Our analysis showed that the size of PP donors was a key variable in paternal success in wild cherry and that membership of multi-ramet clones further increases the chance of paternal success. It is therefore likely that small tree size currently accounts for the low paternal contribution from wood C. Currently none of the trees in wood $\mathrm{C}$ are over $8 \mathrm{~cm} \mathrm{dbh}$, whereas more than $62 \%$ of the trees in woods $A$ and $B$ are in this size category. In addition to this, only one tree in wood $C$ had, thus far, produced further clonal ramets so no individual genet was likely to dominate the local pollen pool. Insect 
pollinator behaviour may have further compounded this result. Several studies have described a foraging restriction of bees to distinct heights (Gumbert and Kunze, 1999 and references therein) and therefore, as flowering was prolific in wood $C$, the pollinators may have been reluctant to move out of these even sized trees into the taller canopy of wood A. It seems likely that the trees from wood $C$ will sire more progeny as they grow in future years. This is of concern, because many of the trees in wood $C$ seem to be of non-local origin and of a highly branched (poor timber producing) 'sweet cherry' phenotype. Although genetic diversity in the introgressed progeny may be increased, this cohort may well prove ill-adapted to local conditions and thus have a negative effect on the adjacent semi-natural woodland.

\section{Characterization of the maternal ecological neighbourhood and factors affecting paternal kinship coefficients within and between maternal progeny} Wild cherry mother trees are likely to be particularly sensitive to their immediate ecological neighbourhood as some trees occur in dense clumps, whereas others grow at a greater distance from their nearest neighbours (Vaughan et al., 2007a,b). In earlier studies, a clumped distribution tended to favour shorter inter-mate distances (Handel, 1983; Garcia et al., 2005). In cherry, the occurrence of clonality and self-incompatibility means that some of the pollen producers in the immediate neighbourhood may be incapable of fertilizing the ovules of some mother trees. It is therefore essential for this species to consider density, self-incompatibility, size and pollinator foraging behaviour when describing the maternal ecological neighbourhood.

We found that the average kinship for pollen gametes within progeny of each mother tree $(F s)$ in cherry was 0.046 which is only slightly lower than the value of 0.060 reported earlier for mature woods of $S$. torminalis (Oddou-Muratorio et al., 2006). This is despite the fact that the densities in the two studies were very different with $\sim 8.4$ genets/ha in cherry compared with $<2$ trees/ha in the $S$. torminalis study site. Oddou-Muratorio et al. (2006) suggest that the higher than random Fs values in Sorbus could result from either correlated pollen dispersal events or from limited mate availability. The fact that we obtained only a slightly lower Fs value in cherry in the much denser population suggests that the pollen kinship within mother tree progeny is because of insect pollinators visiting adjacent flowers on the same tree rather than due to lack of pollen donor availability. At higher floral densities the rate of insect visitation to individual flowers has been shown to be reduced as flowers compete for insect pollinator service (Steven et al., 2003).

Furthermore, studies investigating self-incompatible clover have shown that, in large clones, exogenous pollen on the bee is depleted during the first flower visits, and later visits within the clone produce no fertilizations (Handel, 1985). Thus, the majority of pollinations in clover were probably achieved during the first visits to flowers by insects flying in from beyond the limits of the clone. The subsequent short flights between flowers on the same genet would bring about few effective pollinations. As a result, membership of large clonal patches might be expected to serve as a diversifying factor in terms of pollen receipt with multiple pollen donors contributing to a maternal progeny because of the necessity for many insect visits from beyond the clonal patch. If this is also the case in cherry, then the intraprogeny pollen gamete kinship might be expected to be low in trees belonging to large clonal patches and our results support this. For example, mother trees 5, 6 and 7 are members of the same large clonal group as themselves, and all show low within progeny paternal kinship. In terms of pollen donation this large clonal group seemed to swamp the nearest compatible mother tree (tree 8), as short insect flights between this mother tree and its neighbours which belong to a single large compatible clone would result in successful pollinations. Consequently the progeny of this single ramet tree exhibited the highest kinship of pollen gametes of the ten sampled mother trees.

When considering the effect of self-incompatibility on the ecological neighbourhood of our ten mother trees it was clear that the major factor reducing the number of functional pollen donors in the immediate neighbourhood of each mother tree was clonality (and concomitant self-incompatibility) as opposed to shared $S$ alleles harboured by distinct genets. Our analysis showed significant correlations between the genetic parameter of within progeny pollen gamete kinship of a given mother tree and two ecological characters; namely, the number of compatible trees and the number of trees belonging to the most common compatible clone. In both cases the correlation was significant over a greater distance range when only trees with $\mathrm{dbh}>8 \mathrm{~cm}$ were considered. Thus, genet density, clonality and size are the important ecological determinants affecting the maternal neighbourhood and subsequent pollen gamete kinship within maternal progenies. However, it should be noted that these correlations are based on the progeny of only ten mother trees and analysis of seed from a much greater number of mother trees is required to test these conclusions more thoroughly.

The influence of the size of the pollen donor on its likelihood of success in fathering the seed of a particular mother tree is supported by studies in $S$. torminalis. Hoebee et al. (2007) found that distance among mating partners had a low effect on siring success, whereas size exhibited a larger effect. They attributed this to the fact that in closed forests, only the crowns of large individuals of $S$. torminalis reach into the forest canopy and, therefore attain regular and intense flowering. Likewise in wild cherry floral display is markedly increased when a tree has reached the canopy. The pollen of canopy individuals may have a greater chance of being distributed by insects, although Kreyer et al. (2004) showed that bumble bees regularly fly through closed forests.

When we examined the inter-progeny paternal kinship $(F g h)$ among the ten mother trees we sampled we found that Fgh kinship decreased with distance between mother trees and that the Fgh values never exceeded 0.022. Oddou-Muratorio et al. (2006) also examined the inter-progeny kinship among Sorbus mother trees and also found that they were highest (Fgh 0.045) between mother trees which were close neighbours. The lower inter-progeny paternal kinship in our study probably reflects the fact that there are more candidate pollen donors within any given distance class in our Prunus 
population. However, distance between mother trees was clearly not the only factor. For example tree 8 grows very close to the three clonal mothers 5,6 and 7 but the Fgh kinship for this tree and its three clonal neighbours was low. Again, this is a function of self-incompatibility in this species as the clonal neighbours cannot serve as pollen donors to ramets of their own clone but can be the major pollen donor for the compatible tree 8 which grows within the clonal clump.

The values for intra- $(F s)$ and inter- $(F g h)$ paternal kinship of progeny within and between mother trees 5, 6 and 7 are very similar, indicating that pollinators move within these individuals as much as between them. This clonal group displayed completely synchronous flowering (personal observation Vaughan and Russell) which would encourage movement of pollinators between them. However, there is also an increased probability of transfer between flowers of the same genetic individual i.e. geitonogamy. In self-incompatible species such as cherry, this can lead to a reduction in the proportion of flowers which set fruit due to stigma saturation and compatible pollen limitation (Tarasjev, 2005). It should also be noted that mother trees adjacent to large clonal groups are likely to have relatively homogenous progeny with a high degree of intra-progeny kinship.

\section{Conservation management}

In terms of pollen flow, the mother trees in wood A may be viewed as an integral part of a large continuous population despite the fact that cherry exhibits a fragmented distribution in the landscape. This has important management implications as it indicates that the current distribution of cherry woods does provide an efficient framework for gene flow across the landscape and we should therefore aim to conserve this distribution of woodlands. This also supports the general conclusion of Kramer et al. (2008) that long distance pollen dispersal prevents genetic isolation of forest fragments by allowing the mating population to extend beyond the fragment boundaries.

Currently, wood C, which is of non-local origin, makes only a small contribution to paternity of progeny in wood A. However, this may increase in the future as the trees get bigger and the effect of rare non-local $S$ alleles with a positive frequency-dependent selective advantage is augmented. Such an increased contribution of nonlocal pollen may lead to a reduction in fitness as illadapted genets are incorporated into subsequent generations. Ideally, new woodlands should be established from locally sourced material and planting should be widely spaced to enable patterns of clonality to evolve naturally. In addition to the occurrence of large clonal groups, the relatively high rate of co-paternity we detected in the progeny arrays of some of the mother trees further highlights the importance of basing seed collections on as broad a range of mother trees as possible.

\section{Acknowledgements}

We are grateful to the Woodland Trust for granting access to the study site, to Mr JC Tattershall for assistance in the field and to Mr Glenn Brearley for his reprographic contribution. The work was supported by funding from
Dept. for Environment, Food and Rural Affairs and the Forestry Commission.

\section{References}

Adams WT (1992). Gene dispersal within forest tree populations. New Forests 6: 217-240.

Bacles CFE, Lowe AJ, Ennos RA (2004). Genetic effects of chronic habitat fragmentation on tree species: the case of Sorbus aucuparia in a deforested Scottish landscape. Mol Ecol 13: $573-584$.

Biscaia de Lacerda AE, Kanashiro M, Sebbenn AM (2008). Long pollen movement and deviation from random mating in a low density contiuous population of a tropical tree Hymenaea courbaril in the Brazilian Amazon. Biotropica 40: 462-470.

Broyles SB, Wyatt R (1995). A re-examination of the pollendonation hypothesis in an experimental population of Asclepias exaltata. Evolution 49: 89-99.

Batschelet E (1981). Circular Statistics in Biology. Academic Press: London.

Botstein D, White RL, Skolnick M, Davis RW (1980). Construction of a genetic linkage map in man using restriction fragment length polymorphisms. Am J Hum Genet 32: 314-331.

Campbell JM, Lawrence MJ (1981). The population genetics of the self-incompatibility polymorphism in Papaver rhoeas I. The number and distribution of S-alleles in families from three localities. Heredity 46: 69-79.

De Nettancourt D (2001). Incompatibility and Incongruity in Wild and Cultivated Plants. Springer: Berlin.

Elle E, Meagher TR (2000). Sex allocation and reproductive success in the andromonoecious perennial Solanum carolinense (Solanaceae). II. Paternity and functional gender. Am Nat 156: 622-636.

Devlin B, Clegg J, Ellstrand NC (1992). The effect of flower production on male reproductive success in wild radish populations. Evolution 46: 1030-1042.

Franklin-Tong N, Franklin FCH (2003). Gametophytic selfincompatibility inhibits pollen tube growth using different mechanisms. Trends Plant Sci 8: 598-605.

Garcia C, Arroya JM, Godoy JA, Jordano P (2005). Mating patterns, pollen dispersal, and ecological maternal neighbourhood in a Prunus mahaleb L. population. Mol Ecol 14: 1821-1830.

Garcia C, Jordano P, Godoy JA (2007). Contemporary pollen and seed dispersal in a Prunus mahaleb population: patterns in distance and direction. Mol Ecol 16: 1947-1955.

Geng Q, Lian C, Goto S, Tao J, Kimura M, Islam MS, Hogetsu T (2008). Mating system, pollen and propagule dispersal, and spatial genetic structure in a high-density population of the mangrove tree Kandelia candel. Mol Ecol 17: 4583-4777.

Gerber S, Chabrier P, Kremer A (2003). FAMOZ: a software for parentage analysis using dominant, codominant and uniparentally inherited markers. Mol Ecol Notes 3: 479-481.

Gumbert A, Kunze J (1999). Inflorescence height affect visitation behaviour of bees-a case study in an aquatic plant community in Bolivia. Biotropica 31: 466-477.

Handel SN (1983). Pollination ecology, plant population structure and gene flow. In: Real, L (ed). Pollination Biology. Academic Press: New York. pp 163-211.

Handel SN (1985). The intrusion of clonal growth patterns on plant breeding systems. Am Nat 125: 367-384.

Hardy OJ, Vekemans X (2002). SPAGeDi: a versatile computer program to analyse spatial genetic structure at the individual or population levels. Mol Ecol Notes 2: 618-620.

Hardy OJ, Gonzales-Martinez SC, Colas B, Freville H, Migno A, Olivieri I (2004). Fine-scale genetic structure and gene dispersal in Centaurea corymbosa (Asteraceae). II. Correlated paternity within and among sibships. Genetics 168: 1601-1614. 
Hoebee SE, Arnold U, Düggelin C, Gugerli F, Brodbeck S, Rotach P, Holderegger R (2007). Mating patterns and contemporary gene flow by pollen in a large continuous and a small isolated population of the scattered forest tree Sorbus torminalis. Heredity 99: 47-55.

Knight ME, Martin AP, Bishop S, Osbourne JL, Hale RJ, Sanderson RA, Goulson D (2005). An interspecific comparison of foraging range and nest density of four bumblebee (Bombus) species. Mol Ecol 14: 1811-1820.

Kirby K, Goldberg E (2003). Ancient woodland:guidance material for local authorities. AWG1, English Nature: Peterborough. pp 1-21.

Kramer AT, Ison JL, Ashley MV, Howe HF (2008). The paradox of forest fragmentation genetics. Cons Biol 22: 878-885.

Kreyer D, Oed A, Walther-Hellwig K, Freankl R (2004). Are forests potential landscape barriers for foraging bumblebees? Landscape scale experiments with Bombus terrestris agg. and Bombus pascuorum (Hymenoptera, Apidae). Biol Con 116: 111-118.

Loiselle BA, Sork VL, Nason J, Graham C (1995). Spatial genetic structure of a tropical understory shrub Psychotria officinalis (Rubiaceae). Am J Bot 82: 1420-1425.

Marshall TC, Slate J, Kruuk LEB, Pemberton JM (1998). Statistical confidence for likelihood-based paternity interference in natural populations. Mol Ecol 7: 639-655.

McCubbin AG, Kao TH (2000). Molecular recognition and response in pistil interactions. Annu Rev Cell Dev Biol 16: 333-364.

Meagher TR (1991). Analysis of paternity within a natural pop-ulation of Chamaelirium luteum. II. Patterns of male reproductive success. Am Nat 137: 738-752.

Nei M (1987). Molecular Evolutionary Genetics. Columbia University Press: New York.

Oddou-Muratorio S, Klein EK, Demesure-Musch B, Austerlitz F (2006). Real-time patterns of pollen flow in the wild-service tree, Sorbus torminalis (Rosaceae). III. Mating patterns and the ecological maternal neighbourhood. Am J Bot 93: 1650-1659.

Pasquet RS, Peltier A, Hufford MB, Oudin E, Saulnier LP, Knudsen JT, Herren HR, Gepts P (2008). Long-distance pollen flow assessment through evaluation of pollinator foraging range suggests transgene escape distances. PNAS 105: $13456-13461$.

Ritland K (2002). Extensions of models for the estimation of mating systems using $\mathrm{n}$ independent loci. Heredity $\mathbf{8 8}$ : 221-228.

Routley MB, Kron P, Husband BC (2004). The consequences of clone size for paternal and maternal success in domestic apple (Malus domestica). Am J Bot 91: 1326-1332.

Schoen DJ, Stewart SC (1986). Variation in male reproductive investment and male reproductive success in white spruce. Evolution 40: 1109-1120.
Schueler S, Tusch A, Scholz F (2006). Comparative analysis of the within-population genetic structure in wild cherry (Prunus avium L.) at the self-incompatibility locus and nuclear microsatellites. Mol Ecol 15: 3231-3243.

Smouse PM, Meagher TR (1994). Genetic analysis of male reproductive contribution in Chamaelirium luteum (L.) Gray (Liliaceae). Genetics 136: 313-322.

Steven J, Rooney TP, Boyle OD, Waller DM (2003). Density dependent pollinator visitation and self incompatibility in upper Great Lakes populations of Trillium grandiflorum. J Torrey Bot Soc 130: 23-29.

Stoeckel S, Grange J, Fernandes-Manjarres FJ, Bilger I, FrascariaLacoste N, Mariette S (2006). Heterozygote excess in a selfincompatible and partially clonal forest tree species Prunus avium L. Mol Ecol 15: 2109-2118.

Streiff R, Ducousso A, Lexer C, Steinkellner H, Gloessl J, Kremer A (1999). Pollen dispersal inferred from paternity analysis in a mixed oak stand of Quercus robur L. and Q. petraea (Matt.) Leibl. Mol Ecol 8: 831-841.

Summers K, Amos W (1997). Behavioural, ecological and molecular genetic analyses of reproductive strategies in the Amazonian dart-poison from, Dentrobates ventrimaculatus. Behav Ecol 8: 260-267.

Tarasjev A (2005). Impact of genet size and flowering stage on fruit set in Iris pumila L. clones in wild. Acta Oecol 27: 93-98.

Vallejo-Marín M, O'Brien HE (2007). Correlated evolution of self-incompatibility and clonal reproduction in Solanum (Solanaceae). New Phytol 173: 415-421.

Vaughan SP, Russell K (2004). Characterization of novel microsatellites and development of multiplex PCR for large-scale population studies in wild cherry, Prunus avium. Mol Ecol Notes 4: 512-520.

Vaughan SP, Russell K, Sargent DJ, Tobutt KR (2006). Isolation of $S$ locus F-box alleles in Prunus avium and their application in a novel method to determine self-incompatibility genotype. Theor Appl Genet 112: 856-866.

Vaughan SP, Cottrell JE, Moodley DJ, Connolly T, Russell K (2007a). Distribution of fine-scale spatial-genetic structure in British wild cherry (Prunus avium L.). Heredity 98: 274-283.

Vaughan SP, Cottrell JE, Moodley DJ, Connolly T, Russell K (2007b). Clonal structure and recruitment in British wild cherry (Prunus avium L.). For Ecol Manag 242: 419-430.

Vaughan SP, Bošković RI, Gisbert-Climent A, Russell K, Tobutt KR (2008). Characterisation of novel $S$-alleles from cherry (Prunus avium L.). Tree Genet Genome 4: 531-541.

Wright S (1939). The distribution of self-sterility alleles in populations. Genetics 24: 538-552.

Supplementary Information accompanies the paper on Heredity website (http://www.nature.com/hdy) 